\title{
The New Type of Liquid Chromatography-Colloidal High-Performance Liquid Chromatography (CHPLC): Further Applications
}

\author{
Ilia Brondz \\ Norwegian Drug Control and Drug Discovery Institute (NDCDDI), Ski, Norway \\ Email: ilia.brondz@gmail.com
}

How to cite this paper: Brondz, I. (2018) The New Type of Liquid Chromatography-Colloidal High-Performance Liquid Chromatography (CHPLC): Further Applications. International Journal of Analytical Mass Spectrometry and Chromatography, 6, 51-56.

https://doi.org/10.4236/ijamsc.2018.64005

Received: December 11, 2018

Accepted: December 26, 2018

Published: December 29, 2018

Copyright $\odot 2018$ by author and Scientific Research Publishing Inc. This work is licensed under the Creative Commons Attribution-NonCommercial International License (CC BY-NC 4.0). http://creativecommons.org/licenses/by-nc/4.0/

\begin{abstract}
The recent paper by I. Brondz (2018), "One-Step Procedure for Direct Purification of Pediocin-Like Bacteriocins and Cationic Antimicrobial Peptides from Complex Culture Medium on an Analytical, Semipreparative, and Preparative Scale. A New Type of Liquid Chromatography-Colloidal High-Performance Liquid Chromatography (CHPLC)" (International Journal of Analytical Mass Spectrometry and Chromatography, 6, 41-49, https://doi.org/10.4236/ijamsc.2018.63004), described a new type of CHPLC. This technique allows colloidal liquids and suspensions to be chromatographed directly despite the presence in the liquids of material such as bacteria, fungi, and other soft and hard particles. The significance of this development lies in enabling the single-step cleanup and concentration of the target substance from a complex mixture of soluble molecules in the presence of insoluble particles by high performance liquid chromatography (HPLC). The technique also allows the use of viscose liquids (as described in Brondz (2018) that are not suitable for analysis by conventional HPLC. In the previous paper, emphasis was placed on describing the applications of the techniques for the preparation of target substances such as small peptides, bacteriocins, bacitracin, and lysosome. Normally, the industrial preparation of these substances requires multistep procedures, which are time- and labor-consuming, and typically results in significant loss of target material and specific activity. In the present paper, the application of CHPLC for the isolation of alkaloids from crude raw material such as opium cake is demonstrated. In the opium cake, large amounts of hard vegetable particles and even sand corns are present together with the target alkaloids. Despite this, isolation by CHPLC of the desired compound was achieved in a single step by using a water/ethanol-based liquid. Isolation of alkaloids from such raw materi-
\end{abstract}


al normally requires a multistep procedure that includes the preparation of insoluble tartrate or picrate complex and this process includes dissolving the substance in flammable organic liquid. The isolation described here was performed in a single step by using the water/ethanol-based liquid.

\section{Keywords}

Colloidal High-Performance Liquid Chromatography, Opium Cake, Alkaloids, Morphine

\section{Introduction}

Many pharmaceutical, food, and chemical processes that are employed for the preparation of antibiotics [1] [2], food preservatives [3], and raw materials [4] use fermentation. The preparation of medical alkaloids such as morphine, atropine, hyoscyamine, and scopolamine, and many others, is obtained by extraction from plant materials such as Papaver somniferum L. [5], Atropa belladonna L. [6], and other natural sources that contain these alkaloids. The main interest in alkaloids from Papaver somniferum L. is in morphine, which, despite its harmful effects as a narcotic with strong addictive effects, is still in use as a strong painkiller and anesthetic, analgesic, and antitussive agent. Furthermore, morphine is a raw material for the synthesis of codeine, which has less strong addictive effects and is also used as a painkiller, analgesic, and antitussive agent. Other semisynthetic medical substances are also based on morphine as raw material. Morphine is a natural alkaloid that is obtained from Papaver somniferum L. as opium cake or by extracting the Papaver somniferum grass. In both cases, the raw material is contaminated with insoluble particles; however, the amount of insoluble particles in opium cake is significantly higher than in the grass extract and often includes dust particles and even some sand. Liquids that are prepared from these raw materials also are not ideal and they contain many insoluble particles. The inhomogeneous nature of this material prevents direct chromatographic isolation of individual substances (alkaloids) from these extracts. The preparation of alkaloids through precipitation of alkaloids as insoluble or low-solubility tartrate or picrate salts has been described in closed literature. The precipitated salts are later transformed into the free-base form and individual alkaloids are separated by chromatography or by other means (an exact description of the process of preparation of addictive substances such as morphine is avoided here). The preparation of morphine from the raw material is a labor-, time-, and solvent-consuming operation that involves many steps and is difficult to automate. In the present paper, we used opium cake raw material that was contaminated with high levels of insoluble particles to demonstrate the use of colloidal high-performance liquid chromatography CHPLC [7] to isolate morphine in the chloride salt form directly from the water/ethanol solution of opium cake. In the published previously paper One-Step Procedure for Direct Purification of Pedi- 
ocin-Like Bacteriocins and Cationic Antimicrobial Peptides from Complex Culture Medium on an Analytical, Semipreparative, and Preparative Scale. A New Type of Liquid Chromatography-Colloidal High-Performance Liquid Chromatography (CHPLC) (International Journal of Analytical Mass Spectrometry and Chromatography, 6, 41-49, https://doi.org/10.4236/ijamsc.2018.63004), the method and instrumentations were described. This paper is an application based on CHPLC [7].

\section{Materials and Methods}

Instrumentation was described previously [7]. For Colloidal High-Performance Liquid Chromatography CHPLC analysis, an HP 1100 instrument (Hewlett-Packard, Palo Alto, CA, USA) equipped with a diode array detector and ChemStation software were used. Detection was done at $254 \mathrm{~nm}$ and $360 \mathrm{~nm}$, and a simultaneous UV scan was obtained in the range $190-400 \mathrm{~nm}$. The homemade analytical column was prepared by grafting glass fibers. Glass fibers with a diameter of $0.2 \mu \mathrm{m}$ was used [7]. The homemade analytical column was $150 \mathrm{~mm}$ long with $4.6 \mathrm{~mm}$ internal diameter (i.d.). The homemade injector was a syringe type with a volume of $250 \mathrm{~mL}$. Morphine [8] was used as the standard, and opium cake was donated by former Senior Engineer J. Røe, head of the Analytical Laboratory, Weifa, Oslo, Norway. Ethanol 96\% (EtOH) was obtained from Arcus (Oslo, Norway); other reagents were described previously [7]. For chromatography, the following solutions were prepared: solution 1) glass-distilled purified water; solution 2) $1 \%(\mathrm{w} / \mathrm{w})$ opium cake in glass-distilled purified water containing $10 \%(\mathrm{v} / \mathrm{v})$ ethanol $(96 \%, \mathrm{v} / \mathrm{v}) ; 3)$ eluate number 1 was $0.01 \mathrm{mM} \mathrm{HCl} \mathrm{pH}$ 6.04, eluate number 2 was $1 \mathrm{mM} \mathrm{HCl} \mathrm{pH} \mathrm{3.26.} \mathrm{The} \mathrm{program} \mathrm{was} \mathrm{to} \mathrm{inject} 200$ $\mathrm{mL}$ of solution 2, wash the column with three injector volumes of solution number 1 (each injection of $250 \mathrm{~mL}$ ) (under injection and washing the detector was switched off), then start with $100 \%$ of eluate number 1 with a linear program for $15 \mathrm{~min}$ to $100 \%$ of eluate number 2, hold elution with eluate number 2 for 5 $\mathrm{min}$ and wash with glass-distilled purified water for $5 \mathrm{~min}$. Column flow under the procedure was $5.0 \mathrm{~mL} / \mathrm{min}$.

\section{Results and Discussion}

The isolation and the purity of morphine are shown in below Figure 1 and Figure 2. The fraction from 8.5 to 9.0 min was collected, condensed under vacuum and analyzed with reference to the standard morphine to obtain the Rt and spectrum as described previously [8]. The Rt and spectra confirmed the identity of the obtained substance as morphine. The purity of the fraction from 8.5 to 9.0 min. is more than $95 \%$.

Purity tests are shown in Figures 2(a)-(c).

The spectral tests and purity calculations for the peak integrated from 8.2755 to 9.0355 min are shown in Figure 2(b).

The numerical report for the purity for the peak integrated from 8.2755 to 
Signal DAD1 A, Sig=254,16 Ref=360,100

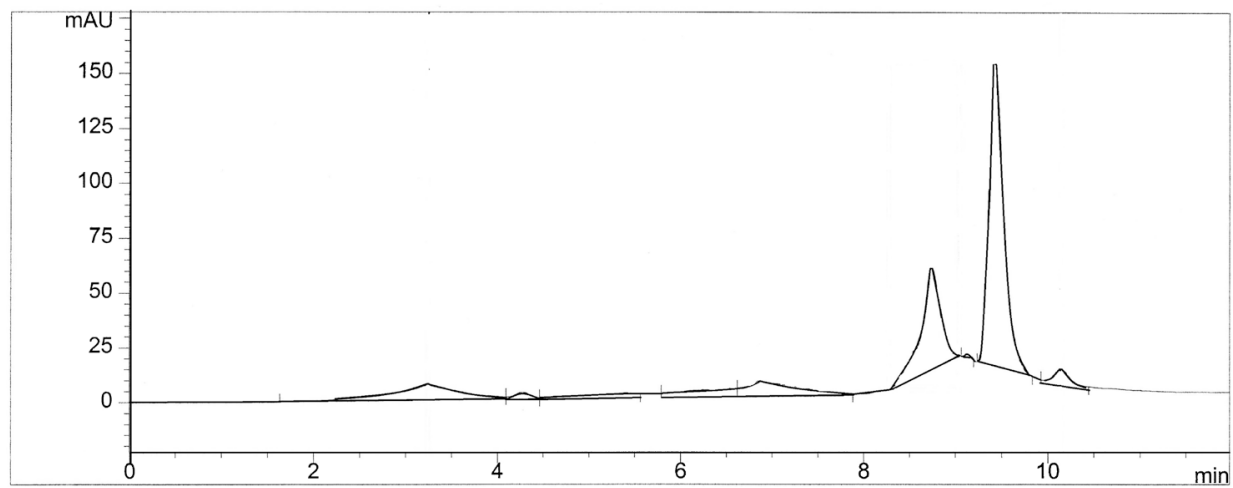

Figure 1. The chromatogram of opium cake; morphine elutes with Rt $8.741 \mathrm{~min}$.

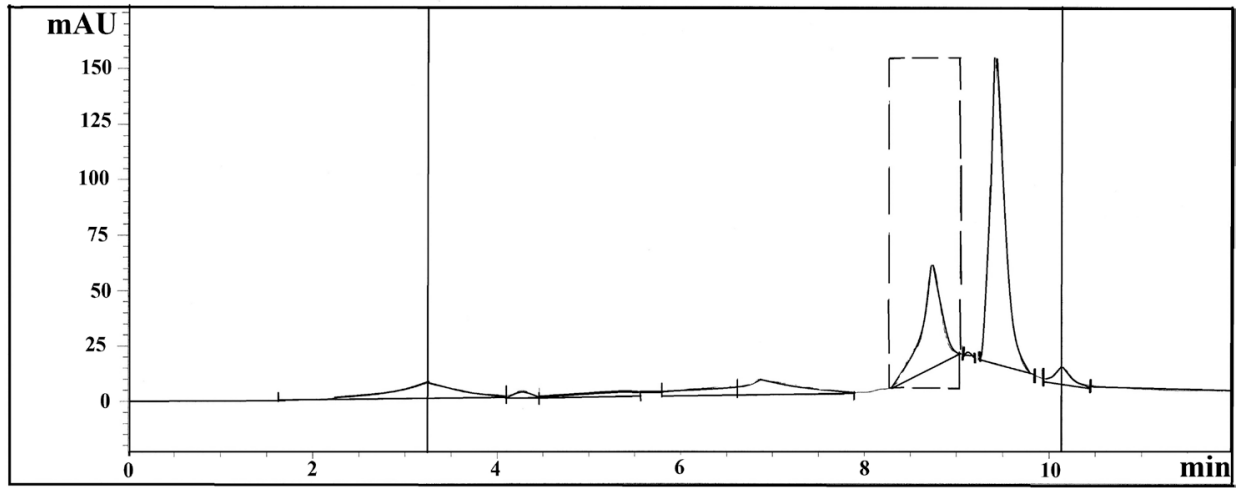

(a)

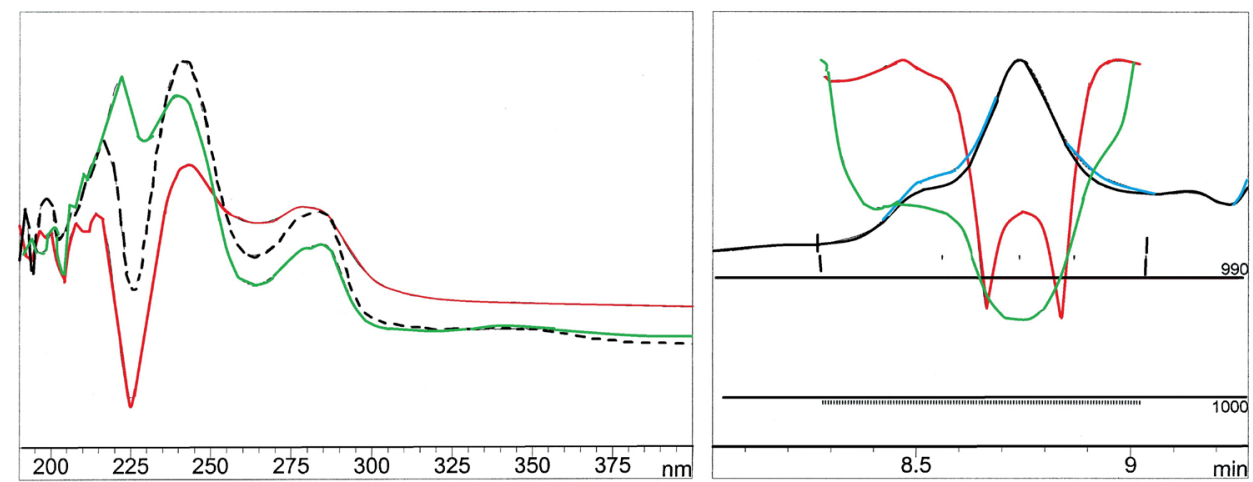

(b)

Purity results peak at $8.741 \mathrm{~min}$.

Signal DAD1 A, Sig=254,16 Ref $=360,100$

The purity factor exceeds the calculated threshold limit.

Purity factor : 470.716 (90\% of spectra exceeds the calculated threshold limit.

Threshold : 910.758 (Calculated with $90 \%$ of all spectra)

Reference : Peak start and end spectra (integrated) (8.2755) $9.0355)$

Spectra : 3 (Selection automatic, 3)

Noise Thres. : 1.196249 (12 spectra, St.Dev $0.5947+3 * 0.2005$ )

(c)

Figure 2. (a) The part of the chromatogram analyzed to assess the purity integrated from 8.2755 to $9.0355 \mathrm{~min}$; (b) (left) The spectra for the peak integrated from 8.2755 to $9.0355 \mathrm{~min}$; (right) graphical presentation of the purity for the peak integrated from 8.2755 to 9.0355 min; (c) Numerical calculations for the purity of morphine peak at $8.741 \mathrm{~min}$. 
$9.0355 \mathrm{~min}$ is presented in Figure 2(c).

\section{Conclusion}

The application of this technique for the isolation of alkaloids from natural extracts is time-, labor-, and solvent-saving, and the isolated alkaloid is of high purity. This technique can be used for a broad spectrum of other alkaloid-containing extracts that are contaminated with particulate matter. Additional research is needed to investigate the isolation of cationic substances from different colloidal and particle-containing liquids.

\section{Acknowledgements}

The author is grateful to former Senior Engineer J. Røe, head of the Analytical Laboratory, Weifa, Oslo, Norway, for the kind donation of standard morphine and opium cake to the head of the R\&D department, Jupiter Ltd., Ski, Norway (under oversight of the Norwegian Drug Control and Drug Discovery Institute (NDCDDI), Ski, Norway) [8].

\section{Conflicts of Interest}

The author declares no conflicts of interest regarding the publication of this paper.

\section{References}

[1] Patnaik, P.R. (2000) Penicillin Fermentation: Mechanisms and Models for Industrial-Scale Bioreactors. Critical Reviews in Biotechnology, 20, 1-15.

https://www.ncbi.nlm.nih.gov/pubmed/10770225 https://doi.org/10.1080/07388550091144168

[2] Hewitt, C.J. and Nienow, A.W. (2007) The Scale-Up of Microbial Batch and Fed-Batch Fermentation Processes. Advances in Applied Microbiology, 62, 105-35. https://www.ncbi.nlm.nih.gov/pubmed/17869604 https://doi.org/10.1016/S0065-2164(07)62005-X

[3] Pasotti, L., Zucca, S., Casanova, M., Micoli, G., De Angelis, M.G.C. and Magni, P. (2017) Fermentation of Lactose to Ethanol in Cheese Whey Permeate and Concentrated Permeate by Engineered Escherichia coli. BMC Biotechnology, 17, 48. https://doi.org/10.1186/s12896-017-0369-y

[4] Hendy, N.A., Wilke, C.R. and Blanch, H.W. (1984) Enhanced Cellulase Production in Fed-Batch Culture of Trichoderma reesei C30. Enzyme and Microbial Technology, 6, 73-77. https://doi.org/10.1016/0141-0229(84)90038-3

[5] Linnæi, C. (1753) Species Plantarum. vol. 1. Laurentius Salvius. 508. https://www.biodiversitylibrary.org/item/13829\#page/520/mode/1up

[6] Linnæi, C. (1753) Species Plantarum. vol. 1. Laurentius Salvius. 181. https://www.biodiversitylibrary.org/item/13829\#page/193/mode/1up

[7] Brondz, I. (2018) One-Step Procedure for Direct Purification of Pediocin-Like Bacteriocins and Cationic Antimicrobial Peptides from Complex Culture Medium in Analytical, Semipreparative and Preparative Scale. The New Type of Liquid Chromatography-Colloidal High-Performance Liquid Chromatography (CHPLC). International Journal of Analytical Mass Spectrometry and Chromatography, 6, 41-49. 
https://doi.org/10.4236/ijamsc.2018.63004

[8] Brondz, I. and Brondz, A. (2012) Supercritical Fluid Chromatography-Mass Spectrometry (SFC-MS) of Heterocyclic Compounds with Trivalent and Pentavalent Nitrogen in Cough Relief Medical Forms Tuxi and Cosylan. American Journal of Analytical Chemistry, 3, 870-876. https://doi.org/10.4236/ajac.2012.312A115 